\title{
A Multivariate Analysis Of Public Housing Residents
}

\author{
James B. KaU and Charles F. Floyd*
}

The United States since 1937 has provided subsidized housing for various lowincome families. The number of subsidized housing units has always been smaller than the total number of available qualified families. In 1970, 7.2 million femaleheads-of-households had incomes less than $\$ 4,000$ per year but only 695,515 public housing units were available. [See Aaron, H. J. (1), p. 11.]

In the City of Savannah in $1972,12,512$ of 38,977 housing units, or 32.1 percent, were classified as substandard. There are only 2,741 public housing units in Savannah and at the present time there are long waiting lists for entry into public housing. ${ }^{1}$ This paper attempts to determine which of the poor have lived in public housing. In other words, given the limited supply of public housing, to what extent is the selection process of the Public Housing Authority biased? The paper also compares the structural and environmental qualities of public housing with those of substandard housing.

Mean values for the economic and social variables presented in the paper are compared between residents of the two types of housing. The results indicate that there are particular groups or characteristics of groups that are significantly different. To test how much these variables discriminate between substandard and public housing residents, a multivariate discriminant analysis is used.

In a study of the urban poor, Anthony Downs (3) found that the aged represent 18 percent of the poor and that 40 percent of the individuals in poverty are represented by female-heads-of-households. But no comparisons were made between the composition of urban poor and those admitted to public housing. Aaron found that in 1970 the median income of the typical public housing tenant under 65 was $\$ 3,636$ and that 70 percent of the tenants were nonwhite. [See Aaron, H. J. (1), pp. 113-118.] In a study of public housing, Roger Starr (9) asked the question, "Which of the poor shall live in public housing?" Starr discussed the selection process of the New York City Housing Authority. He stated that the Authority made a distinction between the working poor and the nonworking poor which included female-heads-of-housholds. Even though actual data on occupancy was not presented, Starr made a case for supporting the restriction of nonworking poor from public housing.

\footnotetext{
*Assistant and Associate Professors, Department of Real Estate and Urban Development, The University of Georgia. The authors wish to thank Michael J. Rowan for his valuable assistance.

1 Waiting lists exceeded vacancies in public housing in 47 of the 49 largest cities in 1967. Building the American City, Report of the National Commission on Urban Problems, H. Doc. 91-34, 91 Cong. 1 sess. (1969), p. 131.
} 
The role of this paper is not to determine the optimal strategy of admission to public housing for the Public Housing Authority but rather to determine exactly what that strategy has been in Savannah.

\section{The Model}

Multiple discriminant analysis is used to test for significant differences between groups and to classify individual observations into one of the groups. It is most appropriately used in situations like the above in which the dependent variable, public and substandard housing residents, can be classified in qualitative form and the independent variables are multivariate.

In multiple discriminant analysis, a set of independent variables that will differentiate between the groups (two in this case) is derived. These independent variables are combined in a linear equation known as the discriminant function and take the form

$$
\mathrm{Z}_{\mathrm{i}}=\mathrm{b}_{\mathrm{o}}+\mathrm{b}_{1} \mathrm{X}_{\mathrm{li}}+\mathrm{b}_{2} \mathrm{X}_{2 \mathrm{i}}+\ldots+\mathrm{b}_{\mathrm{j}} \mathrm{X}_{\mathrm{ji}}
$$

where

$\mathrm{X}_{\mathrm{ji}}$ is the $\mathrm{i}_{\text {th }}$ individual value of the $\mathrm{j}_{\text {th }}$ independent variable,

$b_{j}$ is the discriminant coefficient for the $j_{t h}$ variable,

$\mathrm{Z}_{\mathrm{i}}$ is the $\mathrm{i}_{\text {th }}$ individual discriminant score,

and $Z_{c}$ is the critical value for the discriminant score and is treated here as the mean value of the mean $\mathrm{Z}$ scores for each group.

The classification procedure for the two groups is as follows:

if $Z_{i}>Z_{c}$, classify individual $i$ as belonging to Group 1 ,

if $Z_{\mathrm{i}}<\mathrm{Z}_{\mathrm{c}}$, classify individual $\mathrm{i}$ as belonging to Group 2 .

The primary reason for using multiple discriminant analysis in the paper is that it permits the simultaneous analysis of a set of independent variables associated with each observation. It is assumed that there are two known and identifiable groups and that each observation in the sample belongs to one group only, i.e., the groups are mutually exclusive. It must also be assumed that the independent variables are from a normally distributed population and that the groups' covariance matrices are equal. [For a general discussion of discriminant analysis, see Morrison (6) and Rao (7).]

\section{The Data}

The data consist of a random sample of 149 substandard housing dwellers and 71 public housing dwellers. ${ }^{2}$ All data collected were from the City of Savan-

2The data for this paper were taken from Characteristics of Sub-Standard Housing Residents in Savannah, Georgia, (Monograph, 1973), by Charles F. Floyd and Michael J. Rowan. Prepared for the City of Savannah in cooperation with the Institute of Community and Area Development. 
nah in Georgia. The data were broken into the two categories, public housing residents and substandard housing residents, so that discriminant analysis could be used to analyze the significant differences between the two groups.

Characteristics that could possibly effectively discriminate between the two groups were used in the analysis. The independent variables used to derive the discriminant function consist of the following:

$\mathrm{X}_{1}$ : The number of rooms per housing unit.

$\mathrm{X}_{2}$ : The rent paid by the occupants per housing unit.

$\mathrm{X}_{3}$ : The age of the head-of-household for each housing unit.

$\mathrm{X}_{4}$ : The number of children under 6 years-of-age for each household.

$\mathrm{X}_{5}$ : The number of children between 6 and 18 years-of-age for each household.

$\mathrm{X}_{6}$ : The total family size for each household.

$\mathrm{X}_{7}$ : The gross income for each household.

$\mathrm{X}_{8}$ : The education level, measured as years of schooling, for each head-ofhousehold.

$\mathrm{X}_{9}$ : The existence of plumbing and heating problems, $1=$ problems, $0=$ no problems.

$\mathrm{X}_{10}$ : The existence of rats and other pests, $1=$ problems, $0=$ no problems.

$\mathrm{X}_{11}$ : The existence of waste disposal problems, $1=$ problems, $0=$ no problems.

$\mathrm{X}_{12}$ : The existence of possible fire hazards in the housing unit, $1=$ fire hazard, $0=$ no fire hazard.

$\mathrm{X}_{13}$ : The marital status of the head-of-household, $1=$ married, $0=$ unmarried.

$\mathrm{X}_{14}$ : The employment status of the head-of-household, $1=$ employed, $0=$ unemployed.

$\mathrm{X}_{15}$ : The sex of the head-of-household, $1=$ female, $0=$ male.

$\mathrm{X}_{16}$ : The race of the head-of-household, $1=$ white, $0=$ black.

$\mathrm{X}_{17}$ : Net income, which is gross income minus rental payments, for each household.

$\mathrm{X}_{18}$ : Per capita gross income per household: gross income divided by family size.

$\mathrm{X}_{19}$ : Per capita net income per household: net income divided by family size.

Rents are expected to be lower for the subsidized public housing. It is also hypothesized that public housing will have fewer plumbing and heating and pest 
problems and that fire hazards will be lower. The other variables have no expected sign because there is no theoretical model to explain how the Public Housing Authority in Savannah decides who out of the total number in substandard housing will be allowed to occupy the limited number of public housing units. The discriminant analysis technique used in the paper derives the important variables which made up the discriminant function that the Public Housing Authority used in their selection process.

\section{Empirical Results}

The group means for each of the 19 variables are shown in Table 1. Public housing residents have lower rents and less occurrences of plumbing, pest, and fire hazard problems. This demonstrates that the image of public housing being an unsanitary, vile, and squalid place to live may not be true in all cases. Since most projects have low vacancy rates, ${ }^{3}$ this would suggest that tenants regard

3The vacancy rate for all public housing units on June 30, 1970, was 2.5 percent; it was 1.5 percent or less in 23 states including New York and California. U.S. Department of Housing and Urban Development, 1970 HUD Statistical Yearbook (1971), p. 103.

TABLE 1

\section{GROUP MEAN VALUES OF THE DISCRIMINANT VARIABLES}

\begin{tabular}{llccc}
\hline Variable & $\begin{array}{c}\text { Substandard } \\
\text { Housing }\end{array}$ & $\begin{array}{c}\text { Public } \\
\text { Housing }\end{array}$ & Differences \\
\hline $\mathrm{X}_{1}$ & No. of Rooms & 4.32 & 4.44 & -0.12 \\
$\mathrm{X}_{2}$ & Rent & 50.86 & $28.41^{*}$ & +22.45 \\
$\mathrm{X}_{3}$ Age & 43.49 & $39.70^{* *}$ & +3.79 \\
$\mathrm{X}_{4}$ & Child $<6$ & .54 & $1.21^{*}$ & -.67 \\
$\mathrm{X}_{5}$ & Child 6-18 & .85 & $2.06^{*}$ & -1.21 \\
$\mathrm{X}_{6}$ & Total Family Size & 2.92 & $4.04^{*}$ & -1.12 \\
$\mathrm{X}_{7}$ & Income & 1994.17 & 1906.21 & +87.96 \\
$\mathrm{X}_{8}$ & Education & 8.30 & 8.54 & -.24 \\
$\mathrm{X}_{9}$ & Plumbing and & .23 & $.07^{*}$ & +.16 \\
& Heating Problems & & & \\
$\mathrm{X}_{10}$ & Pests Problems & .41 & $.27^{*}$ & +.14 \\
$\mathrm{X}_{11}$ & Waste Disposal Problems & .19 & .17 & +.02 \\
$\mathrm{X}_{12}$ & Fire Hazards & .14 & $.03^{*}$ & +.11 \\
$\mathrm{X}_{13}$ Marital Status & .22 & .17 & +.05 \\
$\mathrm{X}_{14}$ & Employment & .20 & $.05^{*}$ & +.15 \\
$\mathrm{X}_{15}$ & Sex & .62 & $.79^{*}$ & -.17 \\
$\mathrm{X}_{16}$ & Race & .20 & $.11^{*}$ & +.09 \\
$\mathrm{X}_{17}$ & Net Income & $1565.31^{*}$ & -181.51 \\
$\mathrm{X}_{18}$ & Per-Capita Income & 895.63 & $566.18^{*}$ & +329.45 \\
$\mathrm{X}_{19}$ & Per-Capita Net Income & 576.80 & $438.09^{*}$ & +138.71 \\
\hline
\end{tabular}


public housing as being superior to other sources of housing available to them, as was indicated by the above data. Public housing residents have more children under 6 , more children between 6 and 18, and larger family sizes than the average substandard housing resident. Even though unemployment is greater, gross income levels are not significantly different for public housing residents. Income minus rental payments is higher, reflecting the rental subsidies they receive. Per capita income and per capita net income is lower for public housing residents, thus reflecting the larger family size. The number of blacks and female-headsof-households is significantly greater in public housing and the average age is lower.

The coefficients of the discriminant function are shown in Table 2. Each coefficient measures the contribution of the variable to the $\mathrm{Z}$ score. A relative ranking of the variables is accomplished by adjusting the coefficients by multiplying each one by the standard deviation of the associated variable. This has been done in Table 2 so that the relative importance of each variable in the discriminant function is given.

The relative rankings of the discriminant coefficients indicate that number of children between 6 and 18 is the variable that contributes most in differentiating between groups. Rent, per-capita gross income, age, sex, net income, and race

TABLE 2

COEFFICIENTS AND RELATIVE CONTRIBUTIONS TO VARIABLES

\begin{tabular}{lcrrr}
\hline Variable & $\begin{array}{c}\text { Discriminant } \\
\text { Coefficient }\end{array}$ & $\begin{array}{c}\text { Standard } \\
\text { Deviation }\end{array}$ & $\begin{array}{c}\text { Adjusted } \\
\text { Coefficient }\end{array}$ & $\begin{array}{c}\text { Relative } \\
\text { Rank }\end{array}$ \\
\hline $\mathrm{X}_{1}$ & -.00630 & .906 & -.005708 & 9 \\
$\mathrm{X}_{2}$ & .00069 & 18.531 & .012780 & 2 \\
$\mathrm{X}_{3}$ & .00056 & 17.911 & .010030 & 4 \\
$\mathrm{X}_{4}$ & -.00196 & 1.157 & -.002268 & 11 \\
$\mathrm{X}_{5}$ & -.00308 & 4.866 & -.014987 & 1 \\
$\mathrm{X}_{6}$ & -.00099 & 2.232 & -.002209 & 12 \\
$\mathrm{X}_{7}$ & -.00001 & 891.958 & -.008919 & 8 \\
$\mathrm{X}_{8}$ & .00056 & 3.467 & .001942 & 14 \\
$\mathrm{X}_{9}$ & .00857 & .257 & .002202 & 13 \\
$\mathrm{X}_{10}$ & .00235 & .446 & .001048 & 16 \\
$\mathrm{X}_{11}$ & .00393 & .377 & .001482 & 15 \\
$\mathrm{X}_{12}$ & .00531 & .166 & .000885 & 17 \\
$\mathrm{X}_{13}$ & .00202 & .377 & .000762 & 18 \\
$\mathrm{X}_{14}$ & -.00185 & .232 & -.000429 & 19 \\
$\mathrm{X}_{15}$ & .02399 & .411 & .009865 & 5 \\
$\mathrm{X}_{16}$ & -.02964 & .318 & -.009428 & 7 \\
$\mathrm{X}_{17}$ & -.00001 & 970.997 & -.009709 & 6 \\
$\mathrm{X}_{18}$ & .00003 & 338.951 & .010168 & 3 \\
$\mathrm{X}_{19}$ & .00001 & 274.783 & .002748 & 10 \\
\hline
\end{tabular}


are ranked 2, 3, 4, 5, 6, and 7 respectively. Education, marital status, and gross income all rank low as important discriminatory variables for entry into public housing. The analysis implies that an individual has the best chance of entry into public housing if the person is young, female, black, has children, and has a low percapita income. This is not to say that all inhabitants of public housing are young black females. It is assumed that the Public Housing Authority makes the selection of who shall live in public housing from the available people in substandard housing. If their selection is random, we would expect the same percentage of each variable to be in each sample. The above discriminant analysis, after taking account of sampling error, indicates that the selection process is not random but is biased toward females, blacks, young individuals, and persons with children.

A multivariate F-test of the significance of the differences between two groups can be derived from the mahalanobis D-statistic. In this study the computed F value is 7.24, which is greater than a critical $\mathrm{F}$ of 3.21 with a level of significance of .05 , indicating a significant difference between the two groups.

The mean $\mathrm{Z}$ score and standard deviation of $\mathrm{Z}$ scores for the substandard housing were .02407 and .00003 respectively. For public housing the mean Z was .0085 with a standard deviation of .000025 . Residents with $\mathrm{Z}$ scores greater than .01628 are more likely to be substandard housing residents, and residents with $\mathrm{Z}$ scores less than .01628 are more likely to be in public housing.

To test the discriminating power of the function, each observation is classified by its $\mathrm{Z}$ value into one of two a-priori groups. A classification matrix containing the number of correct and incorrect classifications is shown in Table 3. The sum of correct classifications divided by $\mathrm{N}$, the total sample size, gives the proportion of individuals correctly identified. However, the statistical program in this study uses all $\mathrm{N}$ observations to calculate the discriminant function and then classifies these same $\mathrm{N}$ individuals with this function. This may result in an upward bias. [See Frank, Massy, and Morrison (5).] Since the sample sizes are unequal, the prior probabilities are considered to be proportional to observed sample sizes, which may not give estimates of true prior probabilities. [See Rao (7), p. 577.] In general, when the groups are of unequal size, it may be difficult to interpret the classification table, and the effective sample size is governed by the smaller of the two groups. [See Morrison (6), p. 161.] In the above sample, 63.8 percent are substandard housing residents and 36.2 percent are public housing residents. Given the unequal probabilities of selection, what is the appropriate chance model?

Let $\mathrm{p}$ be the true proportion of Type I individuals and $\alpha$ be the proportion classified as Type II. Then

$$
\mathrm{p}(\text { correct })=\mathrm{p} \alpha+(\mathrm{l}-\mathrm{p})(\mathrm{l}-\alpha) \text {. }
$$

[See Morrison (6), p. 158.] For this study, $\mathrm{p}=\alpha=.362$. Hence the chance proportion correctly classified is $(.362)^{2}+(.638)^{2}=.538$.

The proportional chance criterion is

$\mathrm{Cp}=\alpha^{2}+(1-\alpha)^{2}=.538$. 
The maximum chance criterion,

$\mathrm{Cm}=\max (\alpha, 1-\alpha)=.638$.

Since in this study we wish to correctly identify members of both groups and not just maximize the percentage correctly classified, it is more appropriate to use the chance criterion.

The results of Table 3 indicate that 86.8 percent of the individuals for Group I are classified correctly. The proportional chance criterion is 53.8 percent and the maximum chance criterion is 63.8 percent; therefore, the discriminant function seems significantly classified for Group I. For Group II, 73.3 percent were correctly classified with a chance criterion of 32.7 percent, which is fairly impressive.

The conclusion is that the Public Housing Authority does discriminate and that in general the model has discriminatory power and is able to differentiate between public housing and substandard housing residents.

\section{Summary}

Multiple discriminant analysis has been applied to a study of public housing residents in Savannah. A random sample of 125 substandard housing residents and 71 public housing residents was selected and measures of the characteristics of both the structure and the occupant were computed. A discriminant function was derived using these data to test whether there was in a multivariate sense a significant difference between the groups. The results also give important insight into the specific discriminatory function of the Public Housing Authority.

To test the discriminatory power of the function, the residents were classified by their $\mathrm{Z}$ scores. The discriminant function classified 86.8 percent correctly. Number of children between 6 and 18, per capita income, age, sex, net income, and race were the most important variables. The hypothesis of no significant difference between the two groups was rejected at a .01 level of significance.

\section{TABLE 3}

\section{CLASSIFICATION TABLE FOR SUBSTANDARD HOUSING RESIDENTS (GROUP I) AND PUBLIC HOUSING RESIDENTS (GROUP II)}

\begin{tabular}{lllll}
\hline & & \multicolumn{3}{c}{ Classified } \\
& & 1 & 2 & \\
Actual & 1 & 105 & 16 & 121 \\
& 2 & 20 & 55 & 75 \\
& & 125 & 71 & 196 \\
\hline
\end{tabular}


The results of this study indicate that public housing is helping one group of poor at the immediate cost of another group (the aged and childless poor). The data are for the City of Savannah only, but the results imply that further research into the selection process of the Public Housing Authority would be of interest.

\section{REFERENCES}

1. Aaron, Henry J. Shelter and Subsidies: Who Benefits From Federal Housing Policies?, The Brookings Institution, Washington, D.C., 1972.

2. Aaron, Henry J. Why is Welfare So Hard to Reform?, The Brookings Institution, Washington, D.C., 1973.

3. Downs, Anthony. "Who Are the Urban Poor?", Supplementary Paper 26, Committee for Economic Development.

4. Floyd, Charles F. and Michael J. Rowan. Characteristics of Sub-Standard Housing Residents in Savannah, Georgia, (Monograph, 1973), Institute of Community and Area Development, The University of Georgia, Athens, Georgia.

5. Frank, Ronald E., William F. Massy, and Donald G. Morrison. "Bias in Multiple Discriminant Analysis," Journal of Marketing Research, 2 (August 1965), pp. 250-258.

6. Morrison, Donald G. "On the Interpretation of Discriminant Analysis," Journal of Marketing Research, 6 (May 1969), pp. 156-163.

7. Rao, C. R. Linear Statistical Inference and Its Applications, John Wiley \& Sons, New York, New York.

8. Report of the National Commission on Urban Problems, Building the American City, H. Doc. 91-34, 91 Cong. 1 sess. (1969), p. 131.

9. Starr, Roger. "Which of the Poor Shall Live in Public Housing?", Public Interest, No. 27, Spring 1972, pp. 78-95.

10. U.S. Department of Housing and Urban Development, 1970 HUD Statistical Yearbook (1971). 